\title{
Lateral Internal Sphincterotomy Versus Anal Dilatation In The Treatment of Fissure In Ano-A Single Centre Experience.
}

\author{
Dr.Alok Chandra Prakash. \\ Consultant Surgeon Singhpur Nursing Home,Muri,Ranchi,Jharkhand,India.
}

\begin{abstract}
Anal Fissure is a commonest anal condition of world population and our country is not an exception Lateral Internal sphincterotomy is a surgical option recommended and accepted worldwide. The aim of my study is to compare simple digital anal dilatation versus lateral internal sphincterotomy in terms of final outcome of both the procedure.This study is carried out at singhpur nursing home muri jharkhand during the period of november 2015 to october 2016.A total of 116 patients with idiopathic anal fissure were included in this study of Literal internal sphincterotomy versus simple anal dilatation carried out at our hospital. Operations were performed under Low Spinal anaesthesia and the patients reviewed three weeks later.

Altogether 60 patients were treated by lateral Internal sphincterotomy and 56 by anal dilatation. No serious complications were observed in either group. Two recurrence was observed in the group treated by sphincterotomy, whereas Sixteen recurrence in the other group $(p<005)$. Functional results with respect to impaired control of flatus and soiling of underwear were significantly better after sphincterotomy $(p<0002)$.

It is concluded that lateral Internal sphincterotomy is the treatment of choice for idiopathic anal fissure resistant to conservative measures.
\end{abstract}

Keywords: Anal Dilatation,Lateral Internal Sphincterotomy.

\section{Introduction}

Anal fssure is a very common acute and chronic condition that is presented in majority of the world population. It is the most common cause of severe anal pain. the pain may be so severe that patients may avoid defecation for day's altogether, until they are severely constipated. this delay leads to hardening of the stools, which further tears the anoderm during defecation, setting a vicious cycle. $(1,2)$ the treatment of anal fssure is conservative and surgical .(3) the significant risk of persistent disturbance in anal continence has been reported following lateral sphincterotomy, which varies between $0-36 \%$ for flatus, $0-21 \%$ for liquid incontinence, and 0 $5 \%$ for solid stool incontinence. while the recurrence rate varies from 0-6\% .(4)

the Standard Task Force of the American Society of Colon and Rectal Surgeons has recommended lateral sphincterotomy as the method of choice for the surgical treatment of chronic anal fssures .(5) Surgical procedures for idiopathic chronic anal fissure resistant to conservative treatment include lateral internal sphincterotomy and simple anal dilatation. Which of these is the most favourable,however,is a subject to controversy.

\section{Material And Methods}

All patients presenting to the hospital with idiopathic acute and chronic anal fissure during November 2015 to October 2016 were considered for the trial.A total of 116 patients with idiopathic anal fissure were included in this study of Lateral internal sphincterotomy versus simple anal dilatation carried out at our hospital. Operations were performed under Low Spinal anaesthesia and the patients reviewed three weeks later. Altogether 60 patients were treated by lateral Internal sphincterotomy and 56 by anal dilatation.Patients were accepted provided that induration of the edges of the fissure and exposure of the fibres of the internal sphincter in the floor of the fissure were observed on examination. All operations were carried out under spinal anaesthesia.

Dilatation of the anal sphincters was performed as described by Watts et al.(6)Lateral internal sphincterotomy was always performed on the left side with the patient in the lithotomy position.A small incision was made lateral to the lower edge of the internal sphincter,which was located by the finger.SharpMayo's scissors were introduced and passed up between the internal sphincter and the mucosa with the left index finger inserted into the anus. The inter- sphincteric groove was identified and the intersphincteric plane separated with the scissors.The internal sphincter was then cut with the scissors up to the level of the dentate line.The division was confirmed by inserting the pulp of the index finger into the defect. The skin incision was partially closed with a single Chromic Catgut suture. In three patients an associated sentinel skin tag was excised just before sphincterotomy(two cases)or anal dilatation(one).All patients were allowed home within 24 hours with a dry dressing on the wound and a supply of analgesic tablets.Patients were seen regularly for weekly interval and 
attended for final follow up three weeks after treatment.No patient was lost to follow up.At follow up symptoms were assessed and the anus examined for signs of recurrence.Statistical evaluation was by Fisher's exact test.

\section{Results}

Table-1,Comparison of patients treated by Sphincterotomy and anal dilatation

\begin{tabular}{|l|c|cc|}
\hline & Sphincterotomy & \multicolumn{1}{c|}{ Anal Dilatation } \\
\hline Number of patients & 60 & 56 & $32: 24$ \\
\hline Male : Female & $36: 24$ & 40 \\
\hline Median age & 38 & 11 month \\
\hline Duration of Symptoms & 9 month & 3 weeks \\
\hline Follow up time & 3 weeks & \multicolumn{2}{c|}{} \\
\hline
\end{tabular}

Table-2,Results of Treating Anal Fissure by Sphincterotomy and Anal dilatation

\begin{tabular}{|l|l|l|c|}
\hline & \multicolumn{1}{|c|}{ Sphincterotomy } & $\begin{array}{c}\text { Anal } \\
\text { dilatation }\end{array}$ & Significance \\
\hline $\begin{array}{l}\text { Patients having immediate } \\
\text { pain relief }\end{array}$ & 60 & 54 & NS \\
\hline Patients having complications & $0 \quad$ 3 weeks & 1 & 3 weeks \\
\hline Median time of healing & \multicolumn{1}{|c|}{ N } & $\mathbf{8}$ & NS \\
\hline Number of Recurrence & $\mathbf{2}$ & $\mathbf{5 4}$ & $\mathbf{N S}$ \\
\hline $\begin{array}{l}\text { Patients satisfied with spinal } \\
\text { anesthesia }\end{array}$ & $\mathbf{6 0}$ & $\mathbf{2}$ & NS \\
\hline Number of days off work & $\mathbf{3}$ & & \\
\hline
\end{tabular}

Table-3,Functional Results of Sphincterotomy and Anal Dilatation for Anal Fissure

\begin{tabular}{|l|l|l|l|}
\hline & $\begin{array}{l}\text { Impaired Control of } \\
\text { Flatus }\end{array}$ & $\begin{array}{l}\text { Impaired Control of } \\
\text { Faeces }\end{array}$ & $\begin{array}{l}\text { Faecal soiling of } \\
\text { Underwear }\end{array}$ \\
\hline Sphincterotomy $(\mathrm{n}=60)$ & 0 & 0 & 2 \\
\hline Dilatation $(\mathrm{n}=56)$ & 16 & 4 & 22 \\
\hline Significance & $\mathrm{p}<0.002$ & $\mathrm{NS}$ & $\mathrm{p}<0.002 *$ \\
\hline
\end{tabular}

Fisher's exact test.

Tables 1,II and III give the results of the two treatments. Observations were with respect to immediate relief of pain,healing of the anal fissure,surgical complications, or time off work(TableII). Satisfactory relief of pain and healing of the fissure was achieved in almost all patients.The remaining patient was retreated four weeks later by lateral internal sphincterotomy. two patient treated by anal dilatation developed brisk haemorrhage from the fissure within a few hours after the procedure and was admitted to hospital by his general practitioner. The bleeding was among the 56 patients treated by anal dilatation, eight had symptoms and signs of recurrent fissure later. Of the patients in the other group, only one was observed to have a recurrence $(\mathrm{p}<0-$ 05).All patients with recurrent fissures underwent lateral internal sphincterotomy and the patient discharged from hospital next day. The functional results were significantly better after sphincterotomy than after anal dilatation(tableIII).A functional defect was observed in only two patients treated by lateral Internal sphincterotomy. This patient complained of anal discharge and faecal soiling of underclothes later after treatment. By contrast, in 22 of the 56 patients,treated by anal dilatation faecal soiling was a major problem.Furthermore, 16 of the patients treated by dilatation had impaired control of flatus at the time of follow up, whereas none of the patients treated by lateral internal sphincterotomy suffered from this complication ( $\mathrm{p}<0$ 002). Impaired control of faeces was present in 4 of the 56 patients treated by dilatation compared with none of the patients in the other group. Of all the patients in the sphincterotomy and dilatation treatment groups, 48 and 46 respectively were satisfied with the treatment under spinal anaesthesia (table II) and would have the procedure repeated if necessary.

\section{Discussion}

These findings shows that lateral internal sphincterotomy is better than simple anal dilatation for anal fissure in patients treated under spinal anaesthesia. The recurrence rate of the fissures was significantly higher after anal dilatation than after sphincterotomy, and the functional results with respect to control of flatus and soiling of underwear were significantly better in patients treated by sphincterotomy. Both procedures, however, gave the same degree of immediate relief of pain and healing of the fissures.The study is open to at least one criticism: anal dilatation was done under spinal anaesthesia and although it was performed carefully, some believe that spinal anaesthesia does not permit thorough stretching of the sphincters and that deep genreal anesthesia is required.'All but one of our patients treated by anal dilatation under spinal anaesthesia, however, had immediate relief of pain and healing of the fissure within three weeks. It was only in the longer term that the 
procedure was seen to be inferior to sphincterotomy with respect to the recurrence of fissures. Furthermore, the high incidence of impaired control of flatus and faecal soiling after anal dilatation suggests that the sphincters had been sufficiently stretched with the use of spinal anaesthesia.It is also noteworthy that no complications were observed during the stretching of the sphincters and that most patients in each group were satisfied with the treatment and would accept further treatment under spinal anaesthesia if the alternative meant delay the treatment.

This study has to great extent confirmed the findings of recently published retrospective comparison of the two procedures performed under general anaesthesia.(7)

Our procedure for lateral internal sphincterotomy was easily performed without the use of an anal speculum as advocated by most workers(8) and the results compare favorably without there series. Moreover,most of our patients required only two or three days off work.We conclude that compared with anal dilatation lateral internal sphincterotomy is the treatment of choice for patients with chronic anal fissure. Both procedures are easily and safely performed under spinal anaesthesia.

\section{Reference}

[1]. Ahmad N, Aziz M, Faizullah (2004) Closed lateral internal sphincterotomy under local anesthesia in OPD in the treatment of chronic anal ssure. Ann King Edward Med Uni 10:11-2.

[2]. Farooq A, Niaz Z (2003) Comparative study of lateral internal sphincterotomy verses topical glyceryl trinitrate for treatment of ssure-in-ano. Ann King Edward Med Uni 9: 278-81.

[3]. Sokol T, Marks JW Anal ssure (torn rectum) - causes and treatment options.

[4]. Ram E, Alper D, Stein GY, Bramnik Z, Dreznik Z (2005) Internal anal sphincter function following lateral internal sphincterotomy for anal ssure: a long-term manometric study. Ann Surg 242: 208-11.1 Goligher JC. Surgery of anus, rectum and colon. 4th ed. London: Bailliere Tindall, 1980.

[5]. Lindsay I, Cunningham C, Jones OM, Francis C, Mortensen NJ ( 2004) Fissurectomy-botulinum toxin: a novel sphincter-sparing procedure for medically resistant chronic anal ssure. Dis Colon Rectum 47: 1947-52.

[6]. 6 Watts JM, Bennett RC, Goligher JC. Stretching of the anal sphincters in the treatment offissure-in-ano. Br Med 7 1965;i:342-4.

[7]. 7 Collopy MB, Ryan P. Comparison of lateral subcutaneous sphincterotomy with anal dilatation in the treatment of fissure in ano. MedJ3 Aust 1979;ii:461-2.

[8]. 8 Bailey RV, Rubin RJ, Salvali EP. Lateral internal sphincterotomy. Dis Colon Rectum 1978;21:584-6. 